\title{
PubliDocNet, una fuente de información en línea para la publicidad y la educación
}

\author{
Juan Carlos Marcos Recio \\ Universidad Complutense de Madrid (España)
}

\section{Resumen}

El Portal de Documentación Publicitaria (PubliDocNet) se presenta como una herramienta de trabajo documental en el ámbito de la publicidad y la educación. Se recogen actividades documentales y publicitarias, documentos audiovisuales y nuevas formas de participación por parte de los profesionales de esta disciplina y también de los alumnos. Se muestran estudios estadísticos de uso y participación en las actividades educativas. Se ofrecen los pasos para preparar estrategias publicitarias y las funciones que han de desempeñar los anunciantes y las agencias.

Palabras clave: Publicidad. Documentación. Fondos documentales. Participación del alumno. Enseñanza.

\section{Abstract}

The Advertising Documentation (PubliDocNet) website is presented as a documentary work tool in the area of advertising and education. It covers documentary and advertising activities, audio-visual documents and new forms of participation for the professionals dedicated to this sector and also for the students. Statistical studies on the use and participation in the different educational activities are also reviewed. The steps to be taken in order to draw up advertising strategies and the functions which the advertisers and agencies have to undertake are offered as well.

Keywords: Advertising. Documentation. Documentation archives. Student participation. Teaching.

\section{Introducción}

Tradicionalmente se ha considerado a la publicidad y a las relaciones públicas como una disciplina educativa menor, quizás porque sus estudios han estado más cerca de instituciones privadas y de menor rango que dentro de los estudios superiores universitarios. Otra razón que justifica esa valoración es común a todas las materias de comunicación ya que el intrusismo profesional ha sido muy elevado, de tal forma que una gran mayoría sigue creyendo que publicitario o periodista Scire. 11 : 2 (sep.-dic. 2005) 99-117. ISSN 1135-3761. 
puede ser cualquiera, y además a estas esferas profesionales acuden muchos estudiantes de otras disciplinas.

Un factor determinante es la distancia existente entre el ámbito profesional y las materias educativas. Los primeros se quejan de que los alumnos llegan muy "verdes" a las agencias, sin darse cuenta de que la universidad es una institución que ofrece orientaciones y contenidos globales, pero que, debido a los métodos docentes y las necesidades físicas y técnicas en su desarrollo, no se conseguirá fácilmente que los recién licenciados en cualquier especialidad lleguen a su nuevo puesto de trabajo sabiéndolo todo y con una experiencia importante. La otra parte, los docentes, siguen echando en falta una aproximación profesional y un acercamiento de la universidad para constatar las necesidades reales que exige el mercado laboral y de esta forma adaptar los estudios. La ventaja para las generaciones entrantes en las universidades españolas radica en que las nuevas disciplinas que nazcan a raíz del Programa Europeo de Convergencia ya contemplan estas situaciones y se espera que en pocos años ese abismo entre ambos mundos se reduzca.

Mientras tanto, los docentes han de utilizar los recursos disponibles para que el alumno se sienta identificado con los contenidos y pueda asumir una parte de ellos, además de realizar un número suficiente de prácticas para acercarse más al mundo laboral que va a descubrir tras su paso por las aulas. Así, el objetivo de este artículo es mostrar una herramienta que sirve al alumno en los dos ámbitos, académico (apuntes, foros, encuestas, prácticas, etcétera) y profesional (recogiendo actuaciones en vídeo de jornadas con especialistas en publicidad), que luego estudian y valoran.

Es necesario apuntar que la tarea del profesor tiene su justificación cuando consigue que los alumnos entren en su disciplina y se mantengan todo el curso, siendo conscientes de que el interés por parte del alumno depende de diversas situaciones. Sin embargo, el trabajo desarrollado en PubliDocNet demuestra que la tecnología ha ayudado a los alumnos que han hecho sus prácticas a través de esta herramienta. Los ordenadores no hacen milagros. Detrás de ellos está siempre el ser humano, que es quien en última instancia da la orden (orden-ador: no actúa sin una orden).

El presente trabajo pretende hacer una reflexión sobre las ventajas del uso de herramientas como PubliDocNet para la docencia de la documentación, en este caso aplicada al ámbito de la publicidad y las relaciones públicas. Los resultados anotados tras este primer curso han sido altos, triplicándose el número de prácticas con los alumnos, apoyando la participación entre ellos a través de foros y fomentando el trabajo dentro y fuera de la universidad. La mayor satisfacción que puede recibir un profesor son mensajes como el siguiente de un alumno: "Nunca había trabajado tanto para una asignatura. Y eso que yo no había usado nunca un ordenador". Al final, lo que se ha pretendido - y ya empieza a ser realidad — es poner a dis- 
posición de los alumnos, los profesionales y el trabajo del profesor un instrumento de gestión de las tareas educativas.

\section{Desarrollo tecnológico y documental}

Los nuevos planes de estudio en los que se halla inmersa la universidad española están cada vez más próximos. El Programa de Convergencia en Europa impone como criterio principal a los docentes ofrecer una educación de calidad que sea competitiva y que permita la movilidad de profesores, alumnos y personal administrativo. Para llevar a cabo esas tareas, los desarrollos informáticos basados en las tecnologías de la información y comunicación ya ofrecen herramientas que pueden ser compartidas por los profesores de un mismo departamento, de una facultad con otra de su misma área temática, o entre varias universidades afines.

La globalización ha llegado de esta manera a la educación superior. Profesores y alumnos están entrando en una dinámica de trabajo en la que el uso y consumo de tecnología es elevado. El sistema tradicional de profesor que imparte lección magistral frente a alumnos que escuchan de vez en cuando está siendo remplazado por otras maneras de presentar los contenidos a los docentes. La tan pronunciada frase "como decíamos ayer" está perdiendo valor cada día, pues la relación entre ambos factores educativos no se cierra cuando termina la clase, sino que continúa a través del correo electrónico, del chat o del foro en el que los alumnos discuten entre ellos o con el profesor sobre un tema propuesto en la sesión presencial de clase.

En el ámbito de la documentación, las propuestas docentes innovadoras siguen siendo escasas. La educación refleja los hábitos de trabajo de un colectivo, y en el de la Información y Documentación —nombre que se ha propuesto para los estudios futuros, según las recomendaciones de una comisión presidida por Assumpció Estivill-, son muy poco significativos. En este sentido, hay que señalar que los factores pueden ser varios. En primer lugar, las universidades hasta hace muy poco apenas han dado valor a los estudios basados en la tecnología. En algunos casos, tardaron más tiempo de lo previsto en tener su propia página web y, en otros, la calidad y los contenidos de las mismas siguen siendo bajos, sobre todo porque disponen de facultades de informática y diseño que pueden implementar un mejor producto. En segundo lugar, las facultades y los departamentos siguen una política muy dispersa, de tal forma que se pueden encontrar sitios donde varios profesores de forma aislada trabajan en un espacio común — web site - y otros en los que de manera testimonial y representativa figura un único profesor. Una tercera modalidad del desarrollo tecnológico es la tarea individual de algunos profesores que se empeñan cada curso en ofrecer y mejorar sus apuntes, notas, bibliografía, prácticas, sitios de interés para los alumnos, etcétera.

Scire. $11: 2$ (sep.-dic. 2005) 99-117. ISSN 1135-3761. 
Si se toma como ejemplo el trabajo desarrollado en el Departamento de Biblioteconomía y Documentación de la Universidad Complutense, se observa que todos los procesos anteriores se han ido cumpliendo. Inicialmente, se construyó una página para el departamento que contenía los datos fundamentales de los profesores, con un pequeño currículum de cada uno de ellos y el horario de sus tutorías, además de las prácticas y tareas administrativas del mismo. A raíz de ese trabajo, algunos profesores fueron añadiendo sus tareas docentes a través de las llamadas "páginas personales", es decir, sitios web alojados en un dominio de la universidad, colocadas allí para dar valor y reconocimiento oficial a las propuestas que hacen desde ese sitio a los alumnos.

Paralelamente, desde el Servicio de Documentación Multimedia, dirigido por el catedrático Alfonso López Yepes, se fueron preparando otros trabajos en el ámbito multimedia, como CD-Rom con diversos materiales educativos o DVD de jornadas sobre documentación que recogían las ponencias en imágenes, frente a los textos que se ofrecían en los CD-Rom. Además, la revista Cuadernos de Documentación Multimedia pasó de ser en papel a estar en Internet. Durante un par de años convivieron ambas versiones, hasta que se decidió colocar un número en línea que se fuera actualizando en función de las aportaciones que hacen los autores.

Con esta experiencia tecnológica y con un equipo de profesores y alumnos interesados en diseño tenía que crearse un lugar donde reflejar las acciones que luego servirían para las tareas educativas de cada día. Así aparece el Servicio de Documentación Multimedia (Multidoc) como centro generador de recursos tecnológicos para uso educativo en las diferentes áreas en las que trabaja la Facultad de Ciencias de la Información, es decir, periodismo, publicidad y relaciones públicas, comunicación audiovisual y documentación.

Dentro de Multidoc (1), http://www.multidoc.rediris.es, se encuadraron diversas actividades multimedia con proyección docente. La primera en iniciarse fue CineDocNet, http://multidoc.rediris.es/cinedocnet/index.php, un portal que ofrece diversos contenidos sobre el mundo del cine: desde noticias hasta festivales, premios, etcétera. El segundo de los "hermanos" fue TVDocNet, que siguiendo la misma estructura muestra informaciones en el ámbito de la televisión, la documentación de las imágenes y también una interesante bibliografía de estos temas.

Más recientemente, ya en marcha el curso 2003-2004, se crea PubliDocNet bajo los mismos criterios que sus hermanas mayores, pero desarrollando otras estrategias puesto que la publicidad está presente en todos los ámbitos de la vida. Todo lo que nos rodea es publicidad. Si ustedes giran ahora su cabeza descubrirán alguna marca sobre la camisa que porta su vecino, sobre el bolígrafo que emplea en su escritura o en el fondo de la sala donde se anuncia alguna actividad que patrocina una empresa. Así pues, aunque el camino inicial era el mismo, las necesidades eran diferentes y en este sentido se configuró la herramienta que hace posible su funcionamiento. 


\section{Documentación y publicidad a través de Internet}

En este ambiente de trabajo tecnológico quedaba por determinar cómo aplicar la documentación a la publicidad y las relaciones públicas de tal forma que sirviera para gestionar los contenidos de la asignatura y hacer prácticas. Este es el origen de PubliDocNet. Surge como experiencia de un trabajo colectivo de un profesor con sus alumnos para crear una base de datos que recoja tres tipos de informaciones:

1. Documentación (centros, bibliografía, libros, revistas, artículos, etcétera).

2. Publicidad (agencias, asociaciones, empresas, museos, fotografía, etcétera).

3. Noticias y servicios (pequeñas informaciones sobre publicidad y documentación; agenda para anunciar eventos profesionales o citas de clase: exámenes, conferencias, jornadas...).

Estas tres grandes áreas tienen un denominador común: Internet. Los contenidos que se ofrecen a través de esta herramienta tienen su origen y su destino en la gran Red. Es un punto de partida referencial que permite el enlace a cada uno de los sitios estudiados y analizados. Como docentes y como documentalistas se han de facilitar pasarelas informativas para los alumnos. Así cada uno de los documentos incluidos en esta base de datos permite al usuario obtener el resto de información, ya que desde el nombre o a través de algún elemento gráfico se accede de forma directa al sitio web referenciado.

\section{PublipocNet}

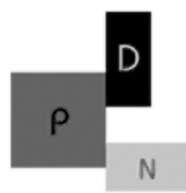

PubliDocNet

Figura 1. Nombre y logotipo creados para el portal de Internet

¿Qué es PubliDocNet? ¿Cuál es su función principal? ¿Qué aporta a la documentación? ¿De qué forma asiste a los profesionales? ¿Qué elementos educativos conjuga para dar servicio a los estudiantes? ¿Quién puede utilizar esta herramienta? A lo largo de este artículo se darán respuestas a estas interrogantes, ya que de esta forma se precisará el funcionamiento de este lugar de Internet.

PubliDocNet, http://multidoc.rediris.es/publidocnet/, es un sitio web especializado en el mundo de la Publicidad y la Documentación (2). Su principal Scire. $11: 2$ (sep.-dic. 2005) 99-117. ISSN 1135-3761. 
objetivo es ser un portal útil para todos aquellos que estudien, investiguen o trabajen en estos ámbitos y para los consumidores habituales, voluntarios o involuntarios, de la publicidad. Es decir, casi todos. La herramienta está pensada para que esos grupos o individuos colaboren en su creación, mantenimiento y actualización de contenidos, de tal forma que entre todos se cree una gran comunidad de intercambio de información para la publicidad y las relaciones públicas, gestionada desde la documentación y con aportes de contenido educativo.

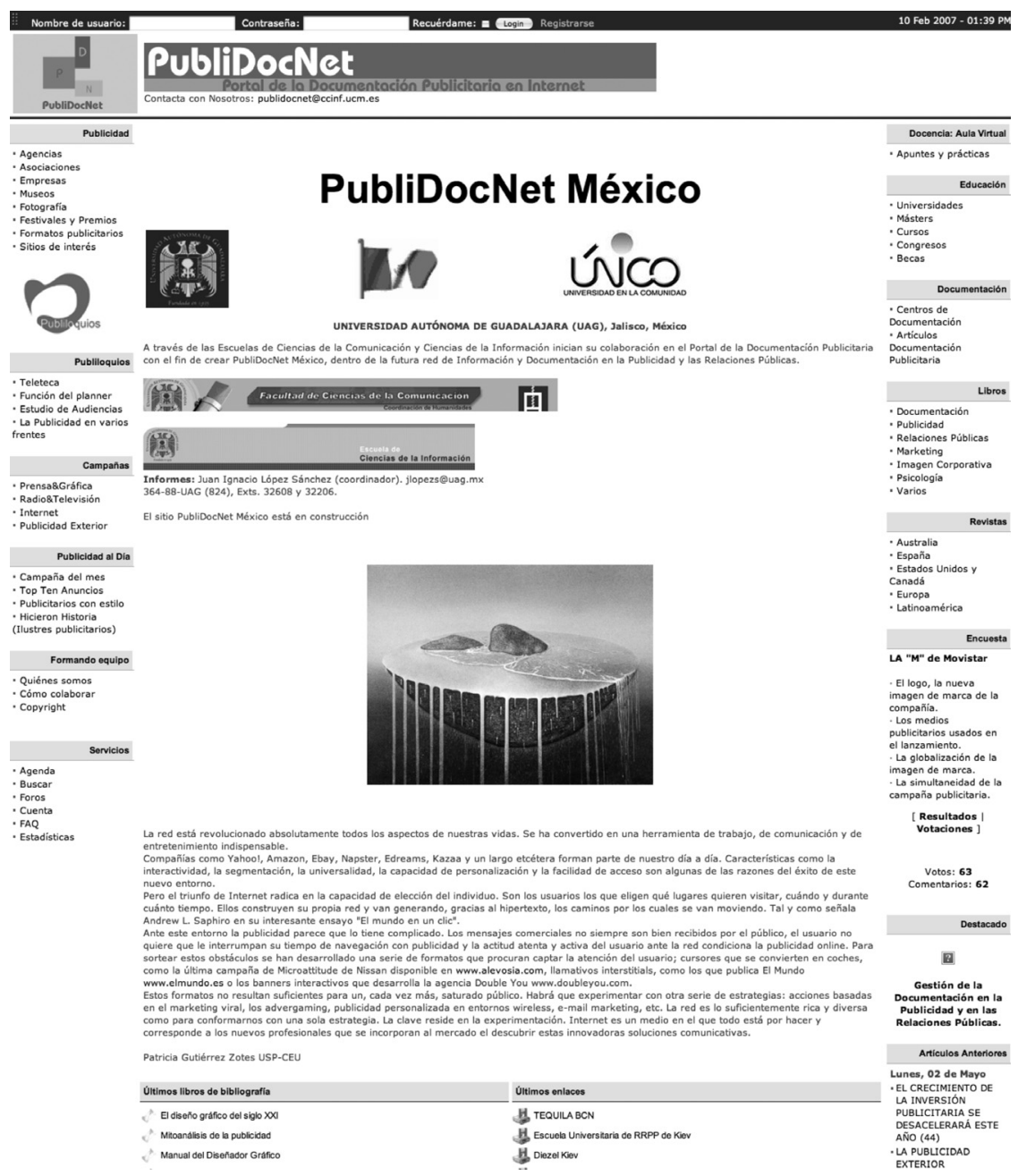

Figura 2. Página principal, en la que se presentan las diferentes secciones

Scire. 11 : 2 (sep.-dic. 2005) 99-117. ISSN 1135-3761. 
En esta base de datos los usuarios encuentran todo tipo de noticias, agencias, campañas de publicidad, vídeos, información sobre libros, becas y en general aquello que pueda interesar del campo publicitario y documental. Como es un sitio interactivo y de fácil consulta, se dispone también de una completa agenda en la que se facilita información sobre eventos, másters, cursos y exposiciones que se realizan en España, indicando datos de interés como la fecha, el lugar, los contenidos, el precio y una manera de ponerse en contacto con los organizadores.

La base de datos está siendo realizada por un equipo de alumnos de Publicidad de la Facultad de Ciencias de la Información, pero en ella ya están participando instituciones y organizaciones que envían sus cursos, eventos, jornadas o actividades para que sean incluidas. La forma de hacerlo es sencilla, puesto que se ofrecen diversas fichas que ya presentan los códigos de HTML que luego convierte la herramienta. El proceso de trabajo es fácil una vez que el usuario se registra y recibe sus claves de acceso. Solo hay que copiar la ficha y rellenarla. Una vez revisada, se envía al administrador y este, en función de su valía, determina si se añade a la base de datos o se borra. En apenas nueve meses se han conseguido cerca de tres mil referencias, no solo textuales, también vídeos, gran cantidad de ejemplos fotográficos, museos con sus imágenes correspondientes y logotipos de empresas, agencias, instituciones, etcétera, que en el trabajo publicitario están muy bien considerados. Ahora, se ahondará más en el reparto de esos fondos en cada una de las tres grandes categorías y sus correspondientes subsecciones.

\subsection{Contenidos documentales}

Una de las características que ofrece en la actualidad cualquier sitio interactivo del estilo de PubliDocNet es una referencia a lugares donde se muestran varios tipos de información. El proceso de gestión y de realización corre a cargo de los documentalistas. El gran campo de actuación son los centros documentales, aunque en la actualidad sea uno de los sitios con menor peso específico.

La estructura general de la base de datos es siempre la misma en todas las secciones. De ahí que se parta en la actualidad de espacios geográficos mayores, como son los continentes, para descender a países y, dentro de estos, a sus especialidades. En una segunda fase, aún en estudio, se pretende separar aquellos contenidos que ofrezcan sitios latinoamericanos para crear lugares independientes por países. Por tanto, los centros de documentación siguen este formato: España, Europa, Estados Unidos y Canadá, Australia y Latinoamérica.

Como esta parte de la herramienta se implementó después, aún son pocos los resultados efectivos introducidos. De tal forma que apenas se constatan cerca de una docena de centros en cada una de las zonas territoriales, excepto en Australia, que ya cuenta con 27. Cuando las cantidades sean importantes se pueden ramificar los centros, pues ahora están mezclados centros de documentación, con archivos

Scire. $11: 2$ (sep.-dic. 2005) 99-117. ISSN 1135-3761. 
o con empresas que disponen de un sitio para gestionar su información o comercializar los fondos documentales.

Otros contenidos de esta sección están representados por una aún incipiente bibliografía, pero que aspira a convertirse en lugar de referencia porque no se queda solo en una ficha bibliográfica y un resumen, sino que se ofrecen comentarios de otros lectores y a su vez se puede hacer una votación para valorar el interés de los lectores sobre esos libros. En este sentido, los docentes están obligados a motivar a sus alumnos para que lean, para que se acerquen a los libros en plan de amigos, no como instrumento para memorizar una serie de definiciones que pronto se olvidan. Para ello, el profesor encarga como tarea la lectura de una serie de libros complementarios y los alumnos han de hacer un pequeño resumen para colocar dentro de la base de datos, además de responder y valorar los que han introducido sus compañeros. Así se crea una comunicación fluida sobre libros de documentación, publicidad, sicología, marketing y hasta de cine o música, pues se ha formulado un campo de "Varios", en el que los alumnos incluyen libros que ya han leído y que tienen alguna conexión con la publicidad. ¿Qué se consigue? Aumentar el nivel de lectura y de formación y la interactividad entre los alumnos que, tras leer un resumen, se pueden interesar o no por un libro determinado. Las secciones creadas hasta ahora son, por este orden, documentación, publicidad, relaciones públicas, marketing, imagen corporativa, sicología y varios.

Las revistas también forman parte de los fondos documentales que se están integrando en PubliDocNet. Así, desde la portada se accede a cada una de las zonas geográficas mencionadas con anterioridad y dentro de cada una de ellas los usuarios las encuentran clasificadas y ordenadas por materias: documentación, publicidad, marketing, relaciones públicas y varios. En los casi nueve meses de trabajo, seis de ellos efectivos con los alumnos, el número de revistas introducidas ha sido el siguiente: España (31), Estados Unidos y Canadá (29), Europa (14), Australia (48) y Latinoamérica (30). De las 31 de España, hay 6 de documentación -Anales de Documentación, Boletín Baratz, Cuadernos de Documentación Multimedia, Document, El Profesional de la Información y Revista de Libros-, 8 de publicidad, 11 de marketing, 6 de "Varios" y ninguna de relaciones públicas. Estas cantidades pueden aumentar en función de que los alumnos o las propias instituciones u organizaciones envíen las informaciones de sus nuevas revistas.

La tercera sección se ha denominado "Artículos" y pretende recoger solo aquellos que relacionan de forma directa la documentación con la publicidad o el resto de contenidos que se ofrecen en el sitio. Si no hay una interconexión, y sobre todo si los elementos documentales son menores, no se aceptarán. Los dos primeros introducidos fueron "Estrategias documentales en agencias de publicidad" y "Evolución y desarrollo de la documentación en el campo publicitario: recursos para optimizar una campaña”. El primero de ellos fue publicado en el número 11 de la 
revista Biblioteconomía y Documentación. El otro apareció en el número 25 de Documentación de las Ciencias de la Información. En ambos se hace una referencia del autor y de cómo localizar el artículo si se ha publicado en papel, y si está en Internet se facilita un enlace para que el usuario pueda acceder al texto completo. Previamente se puede leer un resumen para conocer si el artículo es o no de su interés.

\subsection{Estrategias publicitarias}

Una de las maneras de acercar la universidad al mundo profesional es aproximarse a su terreno. Desde el ámbito documental era necesario proponer, evaluar y crear un espacio que ofreciera datos importantes para los publicitarios. Para ello, se desarrollaron unas fichas básicas sobre los siguientes temas: agencias, asociaciones, empresas, museos, fotografía publicitaria y sitios de interés. Se trata de reunir información que sirva en tres frentes complementarios a la vez:

1. Anunciantes. Pueden acceder a multitud de agencias, conocer sus trabajos y valorar el resultado de algunas campañas; ver alguna estrategia de comunicación, conocer asociaciones de las que ya forman parte o apuntarse a otras nuevas que van surgiendo; apreciar las imágenes de los fotógrafos que trabajan para la publicidad y los premios que han recibido y visitar de forma virtual museos de publicidad y otros donde se recogen importantes obras artísticas.

2. Agencias. Encuentran los mismos requisitos que los anunciantes, pero además pueden hacer un seguimiento de las campañas de la competencia y conocer en qué medios se han incluido, si se trata de Internet, prensa, radio o televisión. Asimismo, acceden de forma directa a su página web y a las de otras agencias.

3. Educación. Los alumnos, investigadores y usuarios en general de la publicidad encuentran de manera sencilla un lugar con amplia información para cualquier trabajo o práctica, o simplemente para saber dónde pueden visualizar una campaña.

Esta sección, dedicada a la publicidad, aborda la necesidad de profundizar en la estructura de las agencias, las asociaciones y las empresas. Sin estos tres elementos, la actividad publicitaria no existiría; de ahí la responsabilidad que tiene la documentación para analizar y conservar todas sus actividades. Los datos que se facilitan son tan solo la punta del iceberg, ya que lo importante de una agencia no es únicamente el mensaje comercial, sino todo el proceso previo de búsqueda, análisis, valoración y utilización final de la información. Y todo ello porque estrategias informativas y documentales se pueden repetir en campañas posteriores, siempre y cuando exista la intención de conservar el material utilizado. Además, como consecuencia de las nuevas tecnologías y la aceptación de la publicidad como elemento comercial que sustentan algunas redes, se ofrece un sitio para conocer los

Scire. $11: 2$ (sep.-dic. 2005) 99-117. ISSN 1135-3761. 
formatos publicitarios que se están utilizando dentro de Internet. Si bien en España el sector tardó en reaccionar frente a las tecnologías, cuando se introdujo lo hizo con fuerza y apostando fuerte. Así, es necesario recoger sitios de interés que puedan servir de faro para guiar a los publicitarios en las diversas facetas de trabajo dentro de una agencia. Y esa es una labor estrictamente documental, es decir, rastrear y descubrir dentro de Internet lugares que ofrezcan contenidos interesantes, no informaciones sobre premios — quizás demasiados ya en publicidad—, sino espacios que traten sobre creatividad, investigación, inversiones, estrategias e incluso que ofrezcan la descarga de alguna campaña.

La imagen es el elemento por excelencia dentro de la publicidad. Es posible que sin un texto preciso, riguroso, medido y metodológico una campaña no tenga éxito. Y también fallará sin una planificación de medios o sin una inversión adecuada. Los factores son muchos, pero la imagen está por encima de todos ellos. Conscientes de esa responsabilidad, en PubliDocNet se pensó desde un principio en introducir elementos visuales a través de los contenidos que gestionan los museos y las asociaciones de fotografía. Con posterioridad se decidió incluir muestras de fotógrafos que han trabajado para la publicidad.

Los museos de publicidad no son muchos, pero desde que llegó Internet el campo se abrió considerablemente. Ahondando más en la cuestión se vio la necesidad de introducir todo tipo de museos, pues la actividad publicitaria es común a todos los sectores. Por ejemplo, El Museo del Automóvil de Buenos Aires es una excelente excusa para mostrar multitud de modelos de coches de otras épocas que pueden servir de referencia ante la creación de un nuevo anuncio de cualquier marca de coches, para ver sus características técnicas, conocer sus formas, estudiar sus diseños, etcétera.

No existe una conciencia documental de guardar y conservar las campañas publicitarias y los recursos informativos, gráficos, sonoros y audiovisuales que se emplean para hacer los anuncios. Una de las razones es que cada acto de comunicación publicitaria requiere un planteamiento nuevo. Pero esto no es del todo cierto, ya que algunos estudios e investigaciones sirven como marco de actuación para varias campañas. El problema es que se extravían por falta de un documentalista que los conserve ordenados para futuras necesidades.

Por otra parte, la llegada de Internet abrió las puertas a particulares que disponían de carteles publicitarios o campañas gráficas y textuales. Parte de sus fondos se han colocado en Internet (véase la figura 4), y otros están a la espera de poder entrar en la Red para ser consultados por los usuarios y consumidores de publicidad. Además, algunas instituciones abrieron sitios en la Red, como es el caso del Museo Virtual de Arte Publicitario del Instituto Cervantes y la Asociación General de Empresas de Publicidad, que ofrece arte publicitario español, arte publicitario contemporáneo, arte publicitario de autor y un taller de restauración y con- 
servación, dentro del cual se llevó a cabo la exposición Memoria de la seducción: carteles del siglo XIX, en la que se recuperaron, restauraron y catalogaron importantes carteles con diversos anuncios publicitarios, especialmente taurinos y de vapor del archivo de la Biblioteca Nacional de España.

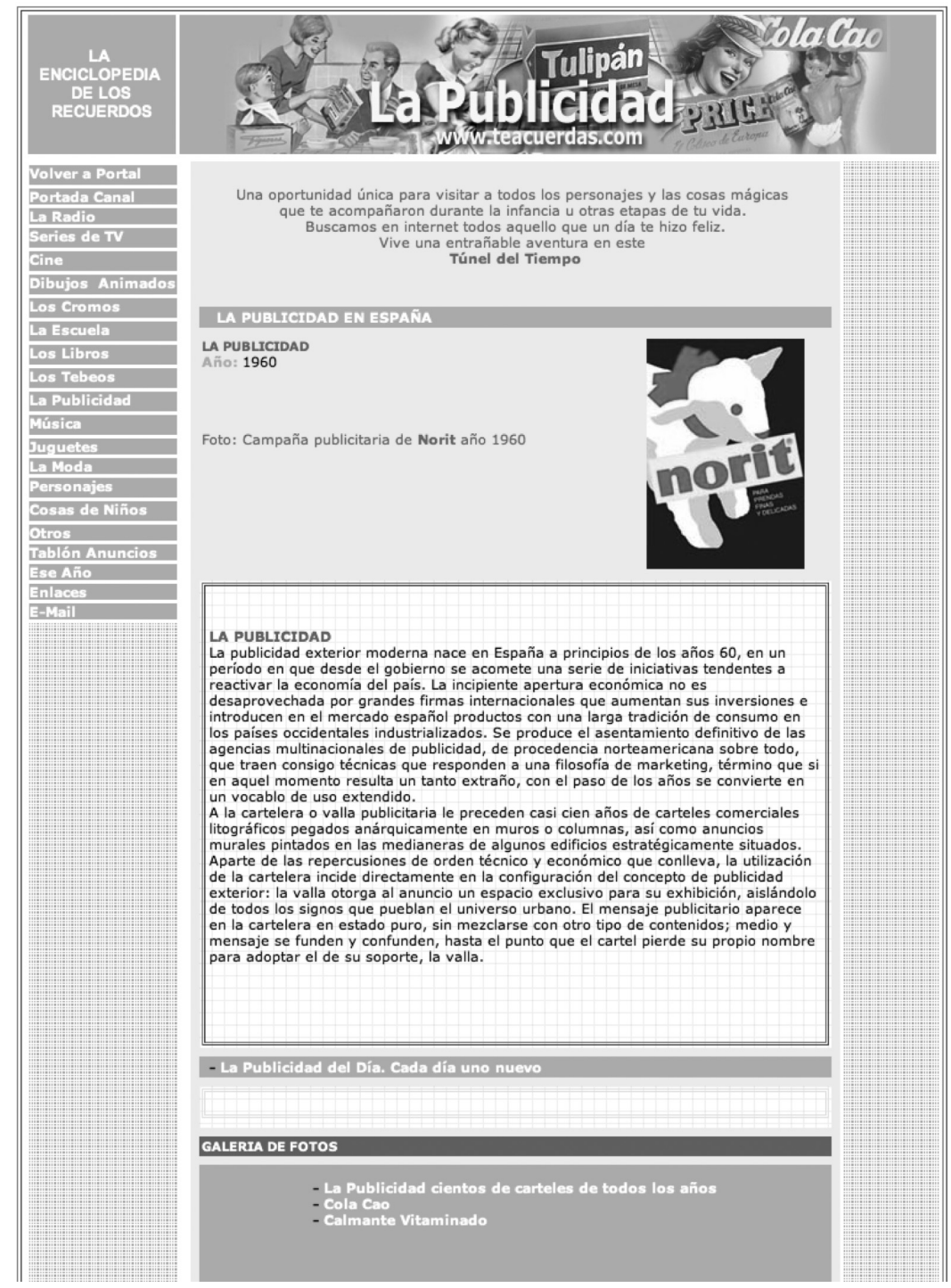

Figura 3. Este museo virtual conserva anuncios gráficos desde 1940.

Scire. 11 : 2 (sep.-dic. 2005) 99-117. ISSN 1135-3761. 


\subsection{Materiales educativos}

El desarrollo dinámico de este sitio de Internet está pensado para que desde él se acceda de forma directa a cursos, jornadas, eventos, estudios y actividades en general del ámbito educativo. Sobre todo porque entre los posibles destinatarios de estos materiales se encuentran los propios alumnos de publicidad de las diferentes facultades, escuelas y centros que imparten esta especialidad.

Los nuevos planes de estudio implantados recientemente en la Facultad de Ciencias de la Información otorgan nueve créditos a la asignatura Documentación Informativa, es decir, tres más que los antiguos planes. Ante esta situación se abría una oportunidad para preparar tres créditos de prácticas y los seis restantes de teoría. De esta forma, se ofrecía la excusa ideal para que los alumnos se implicaran en trabajos prácticos a lo largo del curso.

Uno de ellos dio origen a la creación de la sección "Educación”. Se pretende incluir dentro de ella los estudios reglados en ámbito superior, pero también otros que apoyan o complementan los huecos dejados por las universidades. Así, se recogen instituciones educativas que trabajan para la publicidad, para el marketing, las relaciones públicas o la documentación. Aquí es donde se constata que esta herramienta es una fuente de información para los alumnos. Ellos han de buscar, seleccionar y analizar las universidades que imparten estudios a nivel de licenciatura y rellenar la ficha que podrán ver luego los usuarios en Internet. Como los estudiantes están inmersos en programas de formación que no terminan cuando acaban su licenciatura, pensaron que sería interesante añadir másters, cursos, congresos y becas. Para ello, se crearon las pertinentes fichas y se repartieron las funciones dentro del grupo de trabajo. Cada tres o cuatro grupos comparten un continente y han de conseguir todas las facultades y un interesante cupo de instituciones que apliquen cursos y másters.

En este caso la estructura geográfica se mantiene, pero no la temática, ya que se prefirió reunir todos los cursos y másters que imparte la misma institución para poder tener acceso de forma directa a diversas materias dentro de la publicidad y la documentación, y hacerlo sin tener que regresar constantemente al mismo sitio de Internet. Así, se ofrecen datos de la institución y al mismo tiempo todos los materiales educativos que atesora. Se está pensando, además, en incluir en las universidades todos los cursos y másters que llevan a cabo, ya que hasta ahora solo se ofrecen datos sobre la licenciatura. Asimismo, se recogen congresos de manera más amplia, pero aquí no solo hay datos referenciales, sino que se añade el programa y las diferentes ponencias que se van a exponer.

Queda la sección "Becas", una de las más flojas en cuanto a contenidos, pero que pretende buscar información para asesorar al alumno sobre ayudas, becas, colaboraciones con recursos económicos y entidades que facilitan el acceso al trabajo 
a los estudiantes. El marco es amplio, pero ya existen lugares que ofrecen becas de tipo general. Aquí el alumno encontrará las relacionadas con la publicidad y con la documentación.

Las actividades educativas se completan con una sección: "Publiloquios". En ella se han realizado tres eventos a lo largo del curso 2003-2004. En el primero de ellos estuvo presente Antonio Sabio, un documentalista que lleva más de veinte años en el ámbito publicitario, explicando las ventajas de analizar las campañas y tenerlas listas para cuando las demandan las agencias. Esta tarea la lleva a cabo en la empresa Teleteca, que comercializa un trabajo previo documental sobre los anuncios que se publican en prensa, radio y televisión. El segundo de los actos sirvió para que los alumnos conocieran las funciones que realiza el planner dentro de una agencia. Acudieron tres publicitarios para poner ejemplos prácticos del proceso de investigación y documentación que completa la tarea publicitaria antes de la creación del anuncio. El último se enmarcó dentro de los estudios de audiencias. Cualquier campaña tiene un objetivo claro, pero no siempre es fácil determinar cómo llegar a la gente que ha de consumir ese producto. Hay que saber qué medios lee, que programas de radio escucha o que tiempo dedica a ver la televisión. Y por supuesto está Internet. La jornada evaluaba precisamente todos esos medios y se contó con especialistas de esas áreas temáticas.

Toda la información que se genera de estos actos educativos impartidos por profesionales se graba y luego se introduce en PubliDocNet para que más tarde puedan ser consultadas las propuestas que ofrecieron los publicitarios. Es una manera de generar recursos educativos rentables, pues el acto presencial termina convirtiéndose en una futura clase que se puede impartir a distancia, ya que una vez que se ha visto el vídeo es posible añadir comentarios a través de la encuesta que facilita esta herramienta.

\section{Servicios para la comunidad educativa y profesional}

Tras un tiempo de aproximación a esta herramienta se procedió a implementar otro tipo de recursos educativos. Se pensó que PubliDocNet podría servir para hacer foros con los alumnos, debates, encuestas y al mismo tiempo tener un control sobre el trabajo que estaban realizando desde la sección "Estadísticas". Los primeros pasos se han dado en el ámbito del trabajo práctico. Para ello se proponen temas que sirvan de guía en los foros. Se crean grupos de trabajo y después se descartan los que son similares o los que no se ajustan a las características de la asignatura Documentación Informativa. El alumno ha de contestar primero a cada uno de los foros propuestos y en una segunda práctica ha de responder a lo que han aportado otros compañeros. A partir de ese momento, se abre una interesante interactividad entre ellos. Ha faltado, en todo caso, una mayor participación desde el ámbito profesional, pero aún no han accedido muchos publicitarios a este sitio 
porque no se ha dado a conocer fuera del terreno educativo. Esto se hará en una segunda fase, cuando los contenidos adquieran un nivel óptimo.

Similar en la estructura y en el trabajo docente es la encuesta. A través de ella se han llevado a cabo tres casos prácticos. El alumno ha de visitar en Internet una serie de sitios relacionados con la publicidad, luego evaluarlos, votarlos y, al final, hacer un comentario sobre ellos. Queda luego la opción de contestar a otros alumnos si no se está de acuerdo en sus apreciaciones. El resultado de una de ellas fue el que muestra la siguiente tabla:

\begin{tabular}{|l|r|}
\hline \multicolumn{2}{|c|}{ ¿Cuál de estos sitios de Internet informa más de Publicidad? } \\
\hline Adlatina & $41,67 \%(40)$ \\
\hline Achap & $8,33 \%(8)$ \\
\hline Adforum & $29,17 \%(28)$ \\
\hline Adbusters & $12,50 \%(12)$ \\
\hline Publimark & $1,04 \%(1)$ \\
\hline Canneslions & $0,00 \%(0)$ \\
\hline Mercadeo y Publicidad Total de votos: 96 \\
\hline \multicolumn{2}{|c|}{ Permitimos únicamente un voto por día } \\
\hline
\end{tabular}

Tabla I. Resultados y participación en la segunda práctica de la encuesta

Algunas de las respuestas formuladas por los alumnos fueron las siguientes:

Alumna: Sara (1 C Publicidad). Las propuestas que se formulan son todas interesantes, pero una gran
parte de los publicitarios españoles y los que trabajan en Latinoamérica confían en Adlatina. Por su-
puesto, Mercadeo y Publicidad también muestra interesantes trabajos publicitarios o merece la pena la
relación de links que hay en ACHAP, pero sigo apostando por Adlatina.
Alumna: Carolina (4 A Publicidad). Adlatina es el portal del que más información he obtenido a la hora
de buscar agencias y trabajos en América Latina. Me parece muy bien que se haya creado un sitio donde
se encuentre todo lo necesario para conocer un poco este mundillo. Además con la inscripción se re-
cibe diariamente un correo con todas las novedades de la publicidad.
Alumno: Daniel (1 C Publicidad). Adforum es el más completo de todos y, sobre todo, la característica
que más me ha llamado la atención es la buena organización de la web. Podemos encontrar fácilmente
agencias de cualquier tipo: de publicidad, de comunicación, asociaciones y sindicatos... Además tienes
la oportunidad de encontrar más de 18.455 agencias de publicidad!!!!! Quién lo hubiera sabido antes.
Además encontramos noticias de publicidad, de agencias... Y también un apartado donde se nos informa
de los festivales y eventos más importantes. Espero que a partir de ahora sea una herramienta que pueda
utilizar en mis trabajos...

Tabla II. Algunos de los comentarios de los alumnos participantes en las prácticas de “Encuestas". El resto se puede consultar en dicha sección de la página web. 
El profesor, al evaluar la práctica, puede contestar a un alumno, a un grupo de ellos o a todos. A su vez, los alumnos, lo mismo que sucede en el foro, pueden responderse entre sí haciendo el trabajo práctico más dinámico y más interesante para ellos, a tenor de los resultados obtenidos, pues en ambas secciones la participación ha sido más elevada que en las prácticas tradicionales de otros cursos. Por tanto, el profesor evalúa de forma directa sobre el mismo sitio donde el alumno ha depositado su práctica, ya que al registrarse ha de colocar su nombre y su dirección de correo. Además, en algunas secciones, cuando el profesor revisa, corrige y valida la práctica, el alumno recibe una respuesta automática que le indica que ha sido aceptada y puntuada positivamente. En caso contrario, es decir, si no recibe nada, es que se ha borrado de la base de datos y tendrá que repetirla. También se cuenta con una opción global en estadísticas para saber desde dónde se conectan los usuarios, el tipo de navegador, los días de la semana, la hora más frecuente, etcétera. Estos datos reflejan que en las horas de prácticas de la asignatura es cuando hay mayor participación. Sería deseable para facilitar las tareas docentes que desde el módulo de estadísticas se accediera al trabajo global de un alumno de forma directa; eso resolvería muchos trámites de control cuando se realiza un elevado número de prácticas.

Otro servicio importante como herramienta docente es la "Agenda". Se plantea en una doble dirección. Para informar a los alumnos —exámenes, prácticas, eventos, jornadas, etcétera - y al ámbito profesional —incluyendo actividades, premios, festivales, conferencias, etcétera, sobre publicidad-. Las funciones se separan de manera clara, ya que se pueden elegir colores para cada una de las actividades. En la actualidad solo se emplea el azul para temas educativos y el rojo para los meramente publicitarios, pero se pueden añadir más en función de otras necesidades.

Por último, la sección "FAQ" permite al profesor elaborar una serie de respuestas comunes que luego utilizará cada vez que la duda se repite por parte de más de un alumno. Este módulo simplifica acertadamente el trabajo, pues las tutorías presenciales consisten en repetir muchas veces un concepto que no quedó claro en clase o a la hora de hacer un trabajo. Aquí, en vista de una serie de malentendidos de los alumnos, el profesor ya dispone de un modelo para enviar cada vez que se produce esa situación de incertidumbre en el trabajo del alumno.

\section{Noticias de actualidad del sector: participación de los alumnos de publicidad}

Las informaciones en la actualidad pierden valor pasados apenas unos minutos. Ofrecer los acontecimientos más recientes en el ámbito publicitario y documental exige formalizar un equipo de trabajo que se dedique en exclusiva a mantener actualizado el portal. Esa no es, desde luego, una de las prioridades. Informar

Scire. $11: 2$ (sep.-dic. 2005) 99-117. ISSN 1135-3761. 
sí, pero con las limitaciones que marca el trabajo educativo, al que cada día se dedican más horas, pero que no puede obligar al docente y al alumno a estar todo el día preocupados de esa preparación. Ya existen otros sitios de Internet (Adlatina, LatinSpots, IPMARK, etcétera) que ofrecen informaciones puntuales todos los días.

La propuesta de PubliDocNet es referenciar esos sitios y otros que elaboran contenidos interesantes. De esta forma se cumple una doble función. Por un lado, se acerca al visitante a la actualidad, no la más inmediata, sino la que transcurre dentro de un plazo razonable de tiempo y, por otro, se le ofrece la posibilidad de acceder a la noticia completa al ofrecerle un enlace con el sitio donde se ha publicado el texto completo. Así se contabiliza el número de veces que ha sido leída una noticia. Las que se han introducido desde que se activó el sitio en Internet no han sido muchas. La noticia más leída fue "Análisis del concurso Bush in 30 seconds", con casi un millar de lecturas. Se trataba de una práctica de clase que suscitó un elevado interés porque fue dada a conocer por los medios de comunicación especializados en publicidad y también por los de información general. La noticia informaba sobre una propuesta de la asociación MoveOn.org en la que pedían a los usuarios de Internet que prepararan anuncios sobre la política social del presidente norteamericano. Tenían que criticar la política del presidente de Estados Unidos para luego emitir los anuncios ganadores por la televisión, algo que resultó al final infructuoso, aunque el concurso se realizó y más de 110.000 usuarios de Internet votaron sobre cuáles eran los anuncios que mejor reflejaban ese tipo de política y las acciones del presidente.

Las noticias recogen premios que se entregan en los festivales de publicidad, que son numerosos, avances significativos en algún sector, reconocimiento y méritos para algún profesional y problemas que surgen en la creación de algunas campañas. Temas en los que los alumnos o las facultades son protagonistas también tienen cabida en esta sección. Dos ejemplos ilustran esta parte dedicada a la educación:

- "Remo, la más premiada por los estudiantes de publicidad". El resumen fue elaborado por un alumno:

Los estudiantes de publicidad del Colegio Universitario Domingo de Soto, de Segovia, en el Festival de la Publicidad que vienen haciendo en los últimos doce años, y los de la Universidad Europea de Madrid han elegido las campañas de Remo para Calle 13 como sus favoritas del año 2003. Estas facultades de Publicidad de ambas universidades organizan todos los años un certamen para evaluar la mejor creatividad del año.

- "Nace un máster en Publicidad orientado a la práctica profesional". Resumen: La Universidad Antonio de Nebrija y la agencia FCB Tapsa presentan este curso, dirigido a licenciados sin experiencia laboral que quieren asegurarse un futuro profesional exitoso.

Scire. 11 : 2 (sep.-dic. 2005) 99-117. ISSN 1135-3761. 
Desde algunas de las noticias — estas dos, por ejemplo— se puede hacer el enlace al texto completo y a las instituciones, de tal forma que el alumno puede ampliar y pedir más información a las universidades organizadoras. Junto a estas noticias, la presencia de un texto a modo de editorial acompaña la página principal. Este permanece un tiempo largo hasta que se hace una actualización en profundidad del sitio. Para ello se pide una colaboración a algún experto, pero que no dependa de la actualidad. Ha de ofrecer una orientación publicitaria, recogiendo si es posible una implicación académica y que sea de interés general, ya que la mayoría de los usuarios de esta base de datos son estudiantes de publicidad.

Como la imagen en publicidad ha sido siempre significativa, en la portada se cuida también ese aspecto. Se hacen búsquedas de fotografías que estén libres del pago de derechos y se toman algunas que sirvan como complemento al texto introducido. En algunos casos, la opción que se ha empleado es aportar imágenes de eventos realizados en la facultad y que además de informar sobre los hechos muestren gráficamente el trabajo que realizan los alumnos.

Por último, las secciones y subsecciones ya están muy perfiladas. Así, las modificaciones que se hagan en el futuro serán mínimas. Son los alumnos los que han de ir proponiendo temas de interés que no estén debidamente cumplimentados y entonces se crearán nuevos espacios y colaboraciones.

\section{Conclusiones}

La educación es una actividad que varía constantemente. Los cambios muchas veces son impuestos por la sociedad, más que por el profesor. Ante esta situación, la institución como entidad global —universidad—, los profesores como instrumento de ejecución y los alumnos como parte consumidora han de hacer un esfuerzo conjunto para adaptarse a esos cambios. Los alumnos llegan a la primera práctica asustados, confusos y deseosos de emplear la tecnología. Algunos creen y manifiestan que "esto de los ordenadores no se hizo para mî". Es lo que suelen pensar los primeros días. La respuesta al final del curso es muy diferente: conocen una nueva herramienta de gestión, asumen parte de su trabajo de prácticas y obtienen abundante información para complementar sus estudios sobre becas y cursos.

Desarrollar una herramienta para uso de la docencia en publicidad y relaciones públicas, aplicando los recursos documentales y convirtiendo al alumno en protagonista de las acciones, ha permitido disponer de unos fondos documentales interesantes que servirán de referencia para prácticas de años posteriores — de ahí la importancia de implementar las acciones-y para que otras universidades puedan utilizarlos como marco de trabajo o información.

En apenas medio curso de prácticas se han conseguido estos resultados, aproximadamente: publicidad, 1118; museos, 161; fotografía, 144; educación, 396; centros de documentación, 67; libros, 360; revistas, 152.

Scire. $11: 2$ (sep.-dic. 2005) 99-117. ISSN 1135-3761. 
Fuera de estas grandes cifras hay que incluir las 30 ó 40 noticias que se incluyen por mes, los datos facilitados a través de las encuestas y otras secciones menores que recogen aspectos colaterales de la publicidad. Atrás han quedado prácticas de clase que no siguieron las pautas del profesor y que fueron eliminadas de la base de datos. Ese hueco se fue cubriendo luego por otros alumnos, ya que el paso previo a la hora de aportar algún trabajo práctico exige al alumno comprobar si el documento que quiere crear ya está registrado.

Si una parte importante de los alumnos que han cursado la asignatura Documentación Informativa en el ámbito de la publicidad y las relaciones públicas se han aprovechado de la tecnología para ampliar su conocimiento y creen que la documentación y la gestión de la información han de ser los motores de la actividad principal en el uso de la información, el propósito docente se habrá cumplido; al menos, en este primer año de trabajo. Ahora se abren nuevas interrogantes para mejorar cada una de las secciones, siempre teniendo como punto de mira el trabajo docente y al alumno, que se está convirtiendo en el centro de los estudios. Sin una motivación constante, sin herramientas que complementen la información, sin la ayuda de los departamentos para crearlas, los alumnos a veces se sienten engañados. Un esfuerzo por ambas partes, aprovechando los recursos educativos que nos ofrecen las tecnologías, servirá para que todos cumplan sus compromisos.

\section{Notas}

(1) Tiene su origen en una búsqueda constante dentro del Departamento de Biblioteconomía y Documentación para mejorar las estrategias docentes de los profesores.

(2) Esta herramienta se creó con el fin de ofrecer un lugar a los alumnos para que hicieran sus prácticas fuera del ámbito tradicional en el que emplean papel, CD-Rom o correo electrónico. Luego se ha constatado la validez de realizarlas de este modo, pues no se pierden y están a disposición del resto de alumnos para que puedan leer y comparar sus trabajos.

\section{Referencias}

Amat, N. (1989). Documentación científica y nuevas tecnologías de la información. Madrid: Pirámide, 1989.

Benavides, J. (1997). Lenguaje publicitario. Hacia un estudio del lenguaje en los medios. Madrid: Síntesis, 1997.

Eguizábal Maza, R. (1998). Historia de la publicidad. Segovia: Eresma \& Celeste, 1998.

García Jiménez, A. (1999). La documentación de la publicidad y las relaciones públicas. // García Gutiérrez, A. (ed.). Introducción a la documentación informativa y periodística. Sevilla: Mad, 1999.

García Jiménez, A. (2002). Organización y gestión del conocimiento en la comunicación. Gijón: Trea, 2002.

García Uceda, M. (2000). Las claves de la publicidad. Madrid: ESIC, 2000.

Scire. 11 : 2 (sep.-dic. 2005) 99-117. ISSN 1135-3761. 
González Lobo, M. á. (1998). Curso de publicidad. Madrid: Eresma \& Celeste, 1998.

Malalana Ureña, A. (2002). La documentación en publicidad. // Galdón, G. Teoría y práctica de la documentación informativa. Barcelona: Ariel Comunicación, 2002.

Marcos Recio, Juan Carlos (1999). Desarrollo de aplicaciones documentales: ¿para qué sirve la información en una sociedad global? // Documentación de las Ciencias de la Información. 22 (1999).

Marcos Recio, Juan Carlos (2002). Evolución y desarrollo de la documentación en el campo publicitario: recursos para optimizar una campaña. // Documentación de las Ciencias de la Información. 25 (2002).

Marcos Recio, Juan Carlos (2003). Estrategias documentales en agencias de publicidad. // Biblioteconomía y Documentació. 11 (dic. 2003) 1-15. URL: <http://www2.ub.es/bid/ consulta_articulos.php?fichero=11 marco2.htm $>$.

Marcos Recio, Juan Carlos; García Jiménez, Antonio; Nuño Moral, M. ${ }^{a}$ Victoria (2004). Gestión de la documentación en la Publicidad y en las Relaciones Públicas. Madrid: Síntesis, 2004.

Ortega, E. (1999). La comunicación publicitaria. Madrid: Pirámide, 1999.

Pérez Ruiz, M. A. (1996). Fundamentos de las estructuras de la publicidad. Madrid: Síntesis, 1996. 